\title{
Price-responsive model predictive control of floor heating systems for demand response using building thermal mass
}

Hu, Maomao; Xiao, Fu; Jørgensen, John Bagterp; Li, Rongling

Published in:

Applied Thermal Engineering

Link to article, DOI:

10.1016/j.applthermaleng.2019.02.107

Publication date:

2019

Document Version

Peer reviewed version

Link back to DTU Orbit

Citation (APA):

Hu, M., Xiao, F., Jørgensen, J. B., \& Li, R. (2019). Price-responsive model predictive control of floor heating systems for demand response using building thermal mass. Applied Thermal Engineering, 153, 316-329. https://doi.org/10.1016/j.applthermaleng.2019.02.107

\section{General rights}

Copyright and moral rights for the publications made accessible in the public portal are retained by the authors and/or other copyright owners and it is a condition of accessing publications that users recognise and abide by the legal requirements associated with these rights.

- Users may download and print one copy of any publication from the public portal for the purpose of private study or research.

- You may not further distribute the material or use it for any profit-making activity or commercial gain

- You may freely distribute the URL identifying the publication in the public portal 


\section{Accepted Manuscript}

Price-responsive model predictive control of floor heating systems for demand response using building thermal mass

Maomao Hu, Fu Xiao, John Bagterp Jørgensen, Rongling Li

PII:

S1359-4311(18)36192-1

DOI: https://doi.org/10.1016/j.applthermaleng.2019.02.107

Reference: ATE 13401

To appear in:

Applied Thermal Engineering

\section{APPLIED}

THERMAL

ENGINEERING

$\begin{array}{ll}\text { Received Date: } & 9 \text { October } 2018 \\ \text { Revised Date: } & \text { 10 February } 2019\end{array}$

Accepted Date: $\quad 24$ February 2019

Please cite this article as: M. Hu, F. Xiao, J. Bagterp Jørgensen, R. Li, Price-responsive model predictive control of floor heating systems for demand response using building thermal mass, Applied Thermal Engineering (2019), doi: https://doi.org/10.1016/j.applthermaleng.2019.02.107

This is a PDF file of an unedited manuscript that has been accepted for publication. As a service to our customers we are providing this early version of the manuscript. The manuscript will undergo copyediting, typesetting, and review of the resulting proof before it is published in its final form. Please note that during the production process errors may be discovered which could affect the content, and all legal disclaimers that apply to the journal pertain. 


\title{
Price-responsive model predictive control of floor heating systems for demand response using building thermal mass
}

\author{
Maomao $\mathrm{Hu}^{\mathrm{a}, \mathrm{b}}, \mathrm{Fu} \mathrm{Xiao}^{\mathrm{a}, 1}$, John Bagterp Jørgensen ${ }^{\mathrm{c}}$, Rongling $\mathrm{Li}^{\mathrm{d}}$ \\ ${ }^{a}$ Department of Building Services Engineering, The Hong Kong Polytechnic University, Kowloon, Hong Kong \\ ${ }^{\mathrm{b}}$ Research Institute for Sustainable Urban Development, The Hong Kong Polytechnic University, Kowloon, Hong Kong \\ ${ }^{c}$ Department of Applied Mathematics and Computer Science, Technical University of Denmark, DK-2800 Kgs. Lyngby, \\ Denmark \\ ${ }^{\mathrm{d}}$ Department of Civil Engineering, Technical University of Denmark, DK-2800 Kgs. Lyngby, Denmark
}

\begin{abstract}
Floor heating $(\mathrm{FH})$ system is a widely-used thermally active building system, which can take advantage of building thermal mass to shift energy demands to off-peak hours. Its ability of effective utilization of low-temperature energy resources also helps to increase energy efficiency and reduce greenhouse gas emissions. However, control of FH systems remains a challenge due to the large thermal inertia of the pipe-embedded concrete floor. In the context of smart grids, the control issue becomes more complicated because the dynamic electricity prices need to be taken into consideration to achieve economic benefits and encourage demand response participation. In this study, an advanced optimal control method, i.e., model predictive control (MPC), is developed for FH systems, which can simultaneously consider all the influential variables including weather conditions, occupancy and dynamic electricity prices. Considering the on-line computational efficiency, a control-oriented dynamic thermal model for a room integrated with FH system is developed and represented in a stochastic state-space form. An economic MPC controller, formulated as a mixed integer linear programming problem, is designed for FH systems. A TRNSYS-MATLAB co-simulation testbed is developed to test and compare different control methods under various operating conditions in terms of energy consumption, thermal comfort and operating costs. Test
\end{abstract}

\footnotetext{
${ }^{1}$ Corresponding author. Tel.: +852 2766 4194; Fax: +852 27657198

E-mail address: linda.xiao@polyu.edu.hk
} 
results show that, compared to the conventional on-off controller, the MPC controller is able to use building thermal mass to optimally shift energy consumption to low-price periods, improve thermal comfort at the beginning of occupancy, reduce energy demand during peak periods, and save electricity costs for residential end-users. The weather conditions and electricity prices have influences on the start-up time and duration of preheating, energy flexibility potential and electricity cost savings of FH systems.

Keywords: Floor heating; Model predictive control; Dynamic electricity prices; RC model; Energy flexibility; Demand response.

\section{Nomenclature}

A area, $\mathrm{m}^{2}$

A system matrix in state-space model

$B \quad$ input matrix in state-space model

C equivalent overall thermal capacitance, $\mathrm{J} / \mathrm{K}$

C output matrix in state-space model

C electricity cost

COP coefficient of performance

$d$ disturbance vector

DAP day-ahead electricity price

DR demand response

E energy consumption during a period

E disturbance matrix in state-space model

e slack variable 
f conversion coefficients for heat gains

FF flexibility factor

FH floor heating system

HVAC heating, ventilation and air conditioning system

I global solar radiation

$k \quad$ time step

$K \quad$ Kalman gain

$\dot{m} \quad$ mass flow rate, $\mathrm{kg} / \mathrm{s}$

MPC model predictive control

MAE mean absolute error

$N \quad$ prediction horizon

$P \quad$ covariance matrix of state estimate error

PI proportional-integral controller

$Q$

heat gains, $\mathrm{W}$

$Q \quad$ covariance matrix of process noise

$R$ equivalent overall thermal resistance, $\mathrm{K} / \mathrm{W}$

$R \quad$ covariance matrix of measurement noise

$R C \quad$ resistance-capacitance model

RMSE root mean square error

$T \quad$ temperature, ${ }^{\circ} \mathrm{C}$ 
$u$

input vector

$v$

$w$

$x$

$y$

\section{Greek symbols}

$\rho$

penalty to the slack variable

\section{Subscripts}

$d$

ext

$f l$

in

inlet

int

inter

$m$

mean

O

$p p$ measurement noise

process noise

system state vector

observed output vector in state-space model 


$\begin{array}{ll}\text { solar } & \text { solar radiation } \\ \text { TRN } & \text { TRNSYS } \\ \text { win } & \text { wall } \\ w t & \text { window } \\ & \text { hot water for space heating }\end{array}$

\section{Introduction}

Floor heating $(\mathrm{FH})$ systems have attracted increasing interests and applications in recent years due to various advantages, including almost no noise, efficient use of space, uniform temperature distribution, energy saving potential, and use of environmentally friendly low-temperature energy sources [1, 2]. In Germany, Austria and Denmark, 30-50\% of new residential buildings are equipped with FH systems [2]. In FH systems, hydronic pipe loops are normally embedded in the concrete floor, making the floor thermo-active. The temperature of the water in the pipe can be lower than that in conventional heating systems, e.g., heat radiators, because of the larger surface for heat transfer. This helps to improve the energy efficiency of the heating systems and allows the utilization of low-temperature energy sources, such as solar hot water, geothermal energy, industrial waste heat, etc. Many studies have been carried out on FH systems, including system design [3, 4], system combination with phase change material [5, 6], and system dynamic modeling [7, 8]. However, optimal control of the FH system has remained a challenging issue to be addressed.

Due to the large thermal inertia of the pipe-embedded concrete floor, a large time lag normally exists between the heat supply and the response of indoor air temperature, which could be up to several hours, depending on the pipe depth and thermal capacitance of the floor. Conventional on-off and proportional-integral (PI) control methods lack the ability to compensate for the thermal lag and to promptly respond to the sudden load changes in the thermal space [9]. As a result, the indoor air temperature was usually controlled in a desired temperature range rather than at fixed temperature set point $[2,10]$. A typical control method is to adjust the set point of the water according to the varying outdoor air temperature using heating curves [10]. Besides the weakness in thermal comfort control, the conventional control methods for FH systems hardly fulfilled the 
requirements of peak load reduction and electricity cost saving in the context of smart grids since they seldom took account of the demands of smart grids in the design of control logics.

Today's heating, ventilation and air conditioning (HVAC) systems account for a large portion of the total building electricity use and are the major end users in electricity grids [11-13]. Demand response (DR) of building HVAC systems is considered as one of the most promising solutions to reduce peak power demands, provide energy flexibility and relieve power supply-demand imbalance in electricity grids $[14,15]$. The residential FH systems can use the large thermal inertia of building structure to implement preheating during off-peak/low-price hours in response to dynamic electricity prices. However, two challenging issues remain to be addressed, i.e., when and to what extent to implement the preheating while considering all influential variables, including weather conditions, occupancy, and dynamic electricity prices. A new optimal DR control method is needed for sufficiently addressing these two issues.

Model predictive control (MPC) is an intuitive and well-established approach for constrained control, which was initially applied in the process industries, such as petroleum refineries and chemical plants, in the late 1970s [16]. It merges model-based prediction, numerical optimization and feedback control. MPC has received increasing interests in the field of built environment control in the last decade, and a number of experimental [17-19] and simulation [20-22] studies on it have been conducted. According to different control goals and optimization functions, they can be categorized into: maximizing occupants' thermal comfort [23, 24]; minimizing total energy consumptions[17, 25, 26], operational costs [27-29], or greenhouse gas emissions [21]; minimizing peak load demands[27, 30]; and maximization of the productivity of renewable energy sources[31, 32]. Different optimization objective functions were formulated and solved to meet different requirements.

Applying MPC to built environment control requires suitable control-oriented building thermal models [33]. The models should capture the realistic building thermal dynamics and satisfactorily predict the future evolution, but at the same time has to be computationally efficient. Generally, building thermal models can be classified into three categories: white-box model, black-box model, and grey-box model. The building models in sophisticated simulation software packages, such as EnergyPlus and TRNSYS, adopt white-box approach to predict building thermal performance. The 
major drawbacks of white-box modelling are labor-intensive and time-consuming, which adversely affect their applicability in online control. Black-box models don't require any physical building information, and mainly use statistical tools and machine learning techniques to analyze large amounts of historical data. However, the identified parameters sometimes are difficult to interpret from the physical perspective. This may result in unreliable predictions for the operation conditions which are not covered by training data [33]. Grey-box model, a hybrid of white-box model and black-box model, combines the basic prior knowledge of room thermal features with a reasonable amount of measured data. It has been proven to be effective to predict the building thermal response and has been widely used for MPC due to limited need for physical knowledge and training data [34]. RC (resistance and capacity) thermal network grey-box model is commonly used to describe the thermal dynamics of a building zone [35].

Besides the control-oriented models of building and HVAC system, models of exogenous variables are also required to predict the disturbances over the prediction horizon, including weather conditions, occupancy and occupant behaviors as well as penalty signals from grid operators like dynamic electricity prices and $\mathrm{CO}_{2}$ emissions. The forecasts of weather conditions and penalty signals can be obtained from either third parties or on-site models. The forecasts of occupancy and occupant behaviors usually rely on on-site models based on statistical and machine learning techniques [36]. All models of exogenous variables are subject to uncertainties, which have impacts on the MPC performances [37]. Oldewurtel et al. investigated the impacts of occupancy information on MPC performances [38]. Stochastic and robust MPC controllers were developed in [39, 40] to deal with the uncertainties arising from weather and occupancy forecasts.

In the present paper we aim at developing an MPC method for FH systems in response to dynamic electricity prices to shift peak power demands and provide energy flexibility. Simulation tests are conducted on a TRNSYS-MATLAB co-simulation platform to test the performances of the MPC controller in terms of thermal comfort, energy consumption and electricity costs. Specifically, the major contributions of our study are listed as follows. First, considering online computational efficiency, we develop a control-oriented grey-box dynamic thermal model for a room integrated with FH system. The thermal dynamic model is then transformed from ordinary differential equations to discrete-time linear state-space equations, which is beneficial to formulate convex and easily solved 
optimization problems. Random white noises are added to the state-space model to form a more realistic stochastic model considering the uncertainties arising from exogenous input variables. Second, an economic MPC controller, formulated as a mixed integer linear programming problem, is designed for the FH systems. A Kalman filter is used to estimate the unmeasurable variables and filter the noise from the measurements. Third, a TRNSYS-MATLAB co-simulation testbed is developed to test different control methods under various weather conditions and electricity price profiles. Test results show that compared to conventional on-off control, the MPC controller is able to implement automatic and optimal preheating to shift energy consumption to periods with low electricity prices, resulting in electricity cost savings for residential end-users. The start-up time and duration of preheating and the amount of cost savings depend on the weather conditions and electricity price profiles.

The rest of the paper is organized as follows. In Section 2, we introduce the general implementation structure of MPC for FH systems, which includes offline system model development (Section 3) and online model predictive control (Section 4). In Section 3, we develop and identify a grey-box thermal model to capture the key thermal dynamics in the integrated system, which is represented as a discrete-time linear state-space model. In Section 4, we formulate the MPC controller for FH systems as a mixed integer linear programming problem. In Section 5, we test and compare the performances of the on-off control and MPC using the TRNSYS-MATLAB co-simulation testbed. Finally, the conclusions and future work are presented in Section 6.

\section{Framework of the MPC method for FH systems}

MPC is an advanced control method that can systematically take account of future predictions at the controller design stage, while satisfying the system operating constraints. Its main idea is to use a dynamic model of the system to predict its future evolution and choose the optimal control action. During each sampling interval, beginning at the current state, an optimal control problem is formulated and solved over a finite horizon. The optimization result is a trajectory of future control inputs into a system that satisfy the system dynamics and time-varying constraints. However, only the first control signal is adopted by the system at the next sampling time, whereas the rest of the sequence is discarded. At the following time step, the optimization is repeated based on the updated current state over the next prediction horizon. 
The formulations of cost function, system dynamics, and constraints play significant roles in the performance of an MPC scheme. To obtain simple optimization problems, most cost functions that describe desired performance are convex, such as quadratic costs and linear costs. Due to the computational efficiency, linear constraints are the most common type of constraints, in which the upper and lower bounds of variables are normally used as optimization constraints. The system dynamic models are usually represented in the form of an impulse response model, a step response model, a transfer function model, or a state-space model. For multiple-input and multiple-output (MIMO) systems, the state space model is commonly used to describe system dynamics [22]. Moreover, the state space model can be used to formulate convex and easily solved optimization problems.

As shown in Fig. 1, the implementation structure of MPC for FH systems includes two major parts: data-driven system model development and model predictive control. The system of interest in this study is an integrated building energy system, including a room with mechanical ventilation and a FH system. Considering the computational efficiency, control-oriented models of both the room and the FH system are required. A grey-box RC dynamic room thermal model is developed in the form of ordinary differential equations and then transformed to a discretized state-space model. Instead of using Finite Element and Finite Difference models which are time-consuming and require large inputs, a simplified model for FH systems is used for simple calculation and convenient integration with the room thermal model. The state-space room thermal model and a simplified FH model are adopted in the MPC controller for on-line prediction of the system evolutions under the influence of predicted future exogenous variables such as weather conditions, occupancy and dynamic electricity prices. 


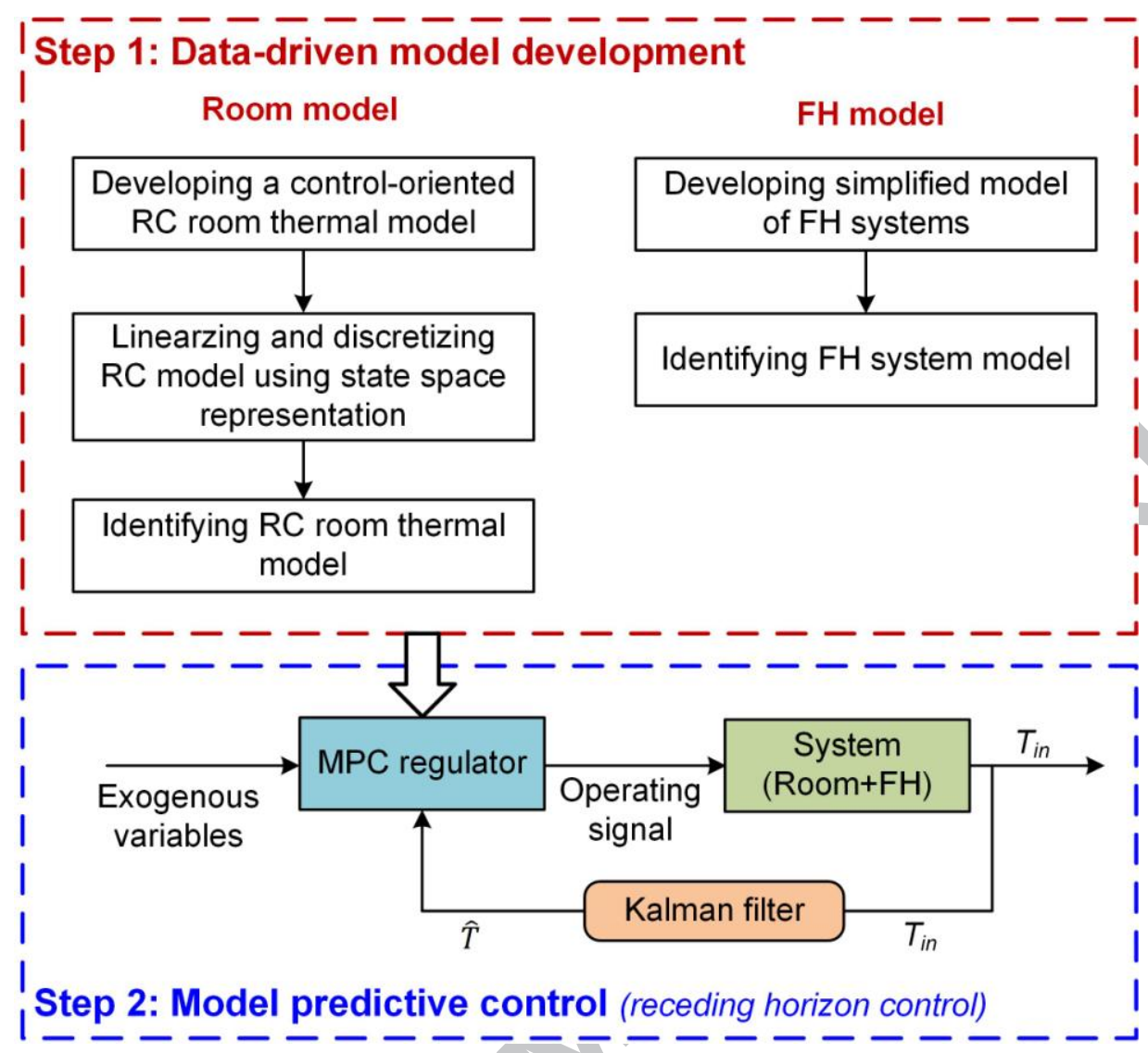

Fig. 1. Block diagram of implementation structure of MPC for FH systems.

\section{Data-driven system model development}

System modeling takes most of the time in the development cycle of a MPC controller, typically around $80 \%$ in the industrial process field and $60 \%$ in the built environment field [35]. The dynamic models of the target system should be readily available for fast online control, which is a multidisciplinary task involving insights into both the air-conditioning engineering and the control engineering in this study.

\subsection{Dynamic thermal model for room with FH system}

\subsubsection{Model development}

The grey-box model should be neither too simple nor too complex. It should capture adequate thermal behaviors of the system to keep its robustness under different operating conditions. Considering the computational efficiency, it should not be too complicated. In general, the room thermal dynamics can be expressed as a set of ordinary differential equations containing several undetermined parameters to be identified. To meet the aforementioned requirements, a control-oriented grey-box 
system thermal model is developed in this study. As shown in Fig. 2, the whole system model consists of an outdoor side, an indoor side, an underfloor side, and a water loop side (heating system).

For the indoor side, it is divided into an exterior envelope $\left(T_{w, \text { ext }}\right.$ and $\left.T_{w, i n t}\right)$, indoor air $\left(T_{i n}\right)$, and an internal thermal mass $\left(T_{m}\right)$. The exterior building envelop includes opaque walls and transparent windows. Two types of heating transfer on the external wall surface are considered, i.e., convective heat transfer with the outdoor air and radiative heat transfer with the sky. Heat flows through the windows consist of (1) conductive and convective heat transfer caused by the temperature difference between outdoor and indoor air, (2) solar radiation incident on the windows, either directly from the sun or reflected from the ground and adjacent buildings. Then solar radiation through the window is absorbed by floor and internal thermal mass constituted of ceiling, partitions and furniture. The bulk of internal thermal mass $T_{m}$ absorbs the heat from indoor heat sources, then gradually transfers the heat into the space by convection. The air in the interior zone is represented by a lumped node, which exchanges heat with the internal thermal mass, internal wall surface, outdoor air through windows, and the heated-up floor. Besides, the internal heat sources from occupants, lights, and equipment are assumed to be immediately absorbed by the indoor air.

The underfloor side provides the thermal interactions between the heating system (water loop side) and the indoor air. It consists of two critical nodes, i.e., floor surface node, $T_{f l}$, and an assumed lumped node of the whole pipe plane, $T_{p p}$. The pipe plane is heated up by the hot water in the pipe and then gradually transfers the heat to the internal surface of the floor via construction elements. The heat transferred from the heating system to the pipe plane is denoted as $Q_{\text {heating. }}$. On the indoor side and the underfloor side, the energy balance for the external and internal wall surfaces $\left(T_{w, e x t}\right.$ and $\left.T_{w, i n t}\right)$, the indoor air $\left(T_{i n}\right)$, the internal thermal mass $\left(T_{m}\right)$, the floor surface $\left(T_{f l}\right)$, and the core of the pipe plane $\left(T_{p p}\right)$ are given by Eqs. $(1)-(6)$ : 


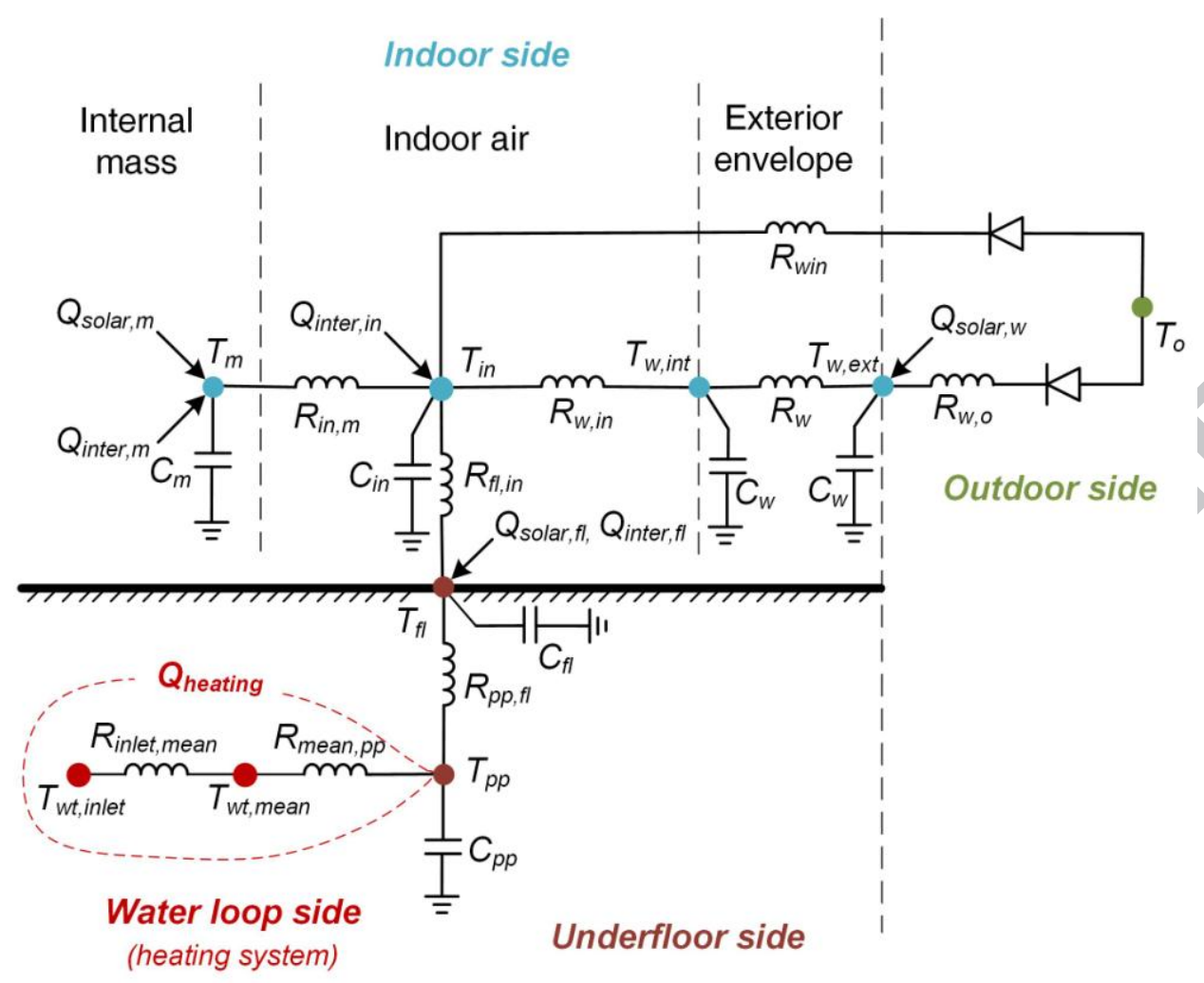

Fig. 2. Schematic of the grey-box RC model for FH systems

$$
\begin{aligned}
& C_{w} \frac{d T_{w, e x t}}{d t}=\frac{T_{o}-T_{w, e x t}}{R_{w, o}}+\frac{T_{w, i n t}-T_{w, e x t}}{R_{w}}+Q_{\text {solar }, w} \\
& C_{w} \frac{d T_{w, i n t}}{d t}=\frac{T_{w, \text { ext }}-T_{w, i n t}}{R_{w}}+\frac{T_{i n}-T_{w, i n t}}{R_{w, i n}} \\
& C_{i n} \frac{d T_{i n}}{d t}=\frac{T_{m}-T_{i n}}{R_{i n, m}}+\frac{T_{w, i n t}-T_{i n}}{R_{w, i n}}+\frac{T_{o}-T_{i n}}{R_{w i n}}+\frac{T_{f l}-T_{i n}}{R_{f l, i n}}+Q_{\text {inter }, \text { in }} \\
& C_{m} \frac{d T_{m}}{d t}=\frac{T_{i n}-T_{m}}{R_{\text {in }, m}}+Q_{\text {solar }, m}+Q_{\text {inter }, m} \\
& C_{f l} \frac{d T_{f l}}{d t}=\frac{T_{i n}-T_{f l} l}{R_{f l, i n}}+\frac{T_{p p}-T_{f l}}{R_{p p, f l}}+Q_{\text {solar }, f l}+Q_{\text {inter }, f l} \\
& C_{p p} \frac{d T_{p p}}{d t}=\frac{T_{f l}-T_{p p}}{R_{p p, f l}}+Q_{\text {heating }}
\end{aligned}
$$

$R$ and $C$ represent the overall heat resistance and capacitance; $T$ denotes temperature; subscripts in, $o$, $w$, int, ext, win, $m, f l, p p$, wt and mean indicate indoor air, outdoor air, exterior wall, internal wall surface, external wall surface, window, internal thermal mass, floor, underfloor pipe plan, circulating hot water in the pipe, and mean water temperature, respectively; $f$ denotes the conversion coefficients for the heat gains, which are also identified together with $R$ and $C$; $Q_{\text {inter }}$ denotes the internal heat gains, which consist of the heat to indoor air $\left(Q_{\text {inter, } \text { in }}=f_{\text {inter, } \text { in }} Q_{\text {inter }}\right)$, floor $\left(Q_{\text {inter,fl }}=\right.$ $\left.f_{\text {inter }, f l} Q_{\text {inter }}\right)$, and internal thermal mass $\left(Q_{\text {inter }, m}=f_{\text {inter }, m} Q_{\text {inter }}\right) ; Q_{\text {solar }}$ denotes the heat gains 
from solar radiation, which include the effect on external wall surface $\left(Q_{\text {solar }, w}=f_{\text {solar }, w} A_{w} I_{\text {solar }}\right)$, internal thermal mass $\left(Q_{\text {solar }, m}=f_{\text {solar }, m} A_{\text {win }} I_{\text {solar }}\right)$, and floor $\left(Q_{\text {solar }, f l}=f_{\text {solar }, f l} A_{\text {win }} I_{\text {solar }}\right)$. $I_{\text {solar }}$ denotes the global solar radiation; $A$ denotes the geometric area.

\subsubsection{Model transformation, discretization and identification}

The dynamic thermal model for room with FH system as described by the ordinary differential equations (1) - (6) is a MIMO system. State space models are commonly used for modeling MIMO systems because of their advantage in explicitly expressing the relationships between the system outputs and inputs. In addition, they can be used to formulate convex optimization problems which in general can be conveniently solved by using state-of-the-art optimization techniques. In order to make the model more realistic, white Gaussian noise is added into the system model. Eqs. (1) - (6) can then be converted into a continuous-time state-space model with unknown stochastic noise, as shown in Eq. (7):

$$
d x=(A x+B u+E d) d t+d w(t)
$$

Where the system state $x=\left[T_{w, \text { ext }} T_{w, \text { int }} T_{\text {in }} T_{m} T_{f l} T_{p p}\right]^{T}$; the input vector $u=Q_{\text {heating }}$; the disturbance vector $\quad d=\left[\begin{array}{llll}T_{o} & I_{\text {solar }} & Q_{\text {inter }}\end{array}\right]^{T} ; \quad$ the $\quad$ system matrix

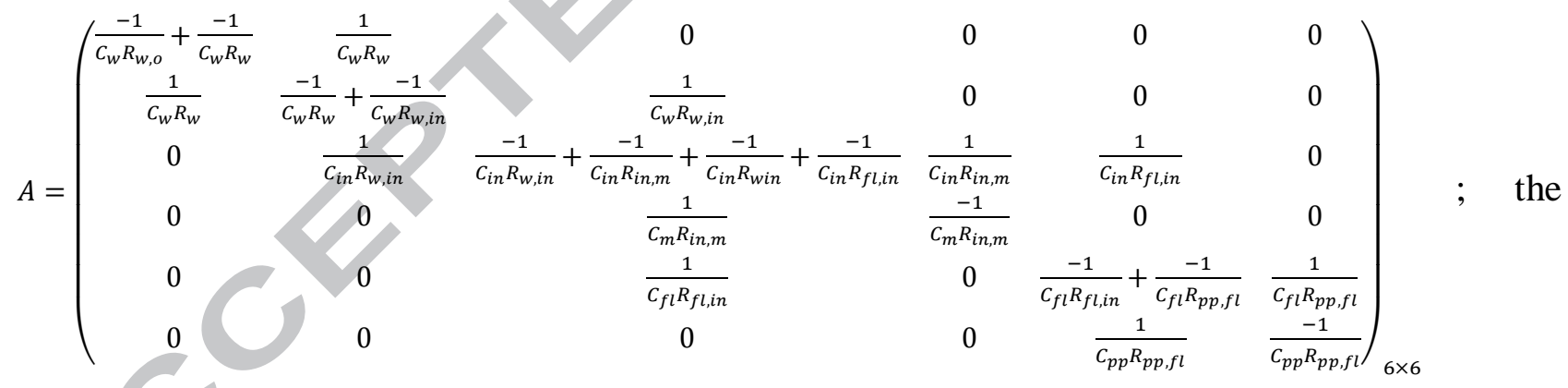

input matrix $B=\left(\begin{array}{llllll}0 & 0 & 0 & 0 & 0 & \frac{1}{c_{p p}}\end{array}\right)^{T}$; the disturbance matrix $E=\left(\begin{array}{ccc}\frac{1}{C_{w} R_{w, o}} & \frac{f_{\text {solar }, w} \times A_{w}}{C_{w}} & 0 \\ 0 & 0 & 0 \\ \frac{1}{C_{\text {in } R_{w i n}}} & 0 & \frac{f_{\text {inter }, \text { in }}}{c_{i n}} \\ 0 & \frac{f_{\text {solar }, m} \times A_{\text {win }}}{C_{m}} & \frac{f_{\text {inter }, m}}{C_{m}} \\ 0 & \frac{f_{\text {solar }, f l} \times A_{w i n}}{C_{f l}} & \frac{f_{\text {inter }, f l}}{C_{f l}} \\ 0 & 0 & 0\end{array}\right)_{6 \times 3}$ $w(t)$ is a Wiener process, which is a stochastic process with independent normal distributed increments, $d w(t) \sim N(0, Q)$.

In practical applications, the stochastic continuous-time state-space model needs to be discretized, and the stochastic discrete-time state-space model are given by Eqs. (8) - (9). 


$$
\begin{gathered}
x_{k+1}=A_{d} x_{k}+B_{d} u_{k}+E_{d} d_{k}+w_{k} \\
y_{k}=C_{d} x_{k}+v_{k}
\end{gathered}
$$

where $A_{d}, B_{d}$ and $E_{d}$ are the corresponding matrices of the discrete-time state-space model which depend on the sampling time. The observed output vector $y_{k}=\left[T_{\text {in }} T_{f l}\right]^{T}$; the output matrix $C_{d}=\left(\begin{array}{llllll}0 & 0 & 1 & 0 & 0 & 0 \\ 0 & 0 & 0 & 0 & 1 & 0\end{array}\right)_{2 \times 6}$; The random variables $w_{k}$ and $v_{k}$ represent the process and measurement noises, respectively, which are assumed to be independent, white and with normal distribution probabilities, i.e., $w_{k} \sim N\left(0, Q_{d}\right)$ and $v_{k} \sim N(0, R) ; Q_{d}$ and $R$ are covariance matrices of process noise and measurement noise, respectively. Eqs. (9) - (10) are used in the MPC controller to predict the system evolutions.

Prior to being used for on-line prediction, the grey-box room thermal model consisting of a set of undetermined parameters needs to be identified using historical data from either field tests or simulation tests. Identification methods for state-space MIMO models can be classified into grey-box and black-box identification methods. Black-box identification methods, such as subspace identification methods, are widely used in industrial control filed due to simple parametrization and non-iterative numerical solution $[41,42]$. However, since the subspace identification methods completely rely on historical data and statistical approaches, the identified parameters may not be physically reasonable $[43,44]$. In this study, the state-space MIMO model is estimated using the iterative grey-box identification method which minimizes the prediction errors. The identification process is implemented using the ssest function available in System Identification Toolbox of MATLAB [45].

\subsection{Model of FH systems}

\subsubsection{Model development}

For the FH system, i.e., water loop side, it is critical to determine the amount of the transferred heat $\left(Q_{\text {heating }}\right)$ and outlet water temperature $\left(T_{w t, o u t l e t}\right)$ given the mass flow rate $\left(\dot{m}_{w t}\right)$, inlet hot water temperature $\left(T_{w t, i n l e t}\right)$, and the core temperature of the pipe plane $\left(T_{p p}\right)$. Considering the key thermal dynamics in the pipe, we divided the whole heat transfer process into two major steps: (1) heat transfer from inlet water $\left(T_{w t, \text { inlet }}\right)$ to the point with mean water temperature $\left(T_{w t, m e a n}\right)$ and (2) heat transfer from the point with mean water temperature $\left(T_{w t, m e a n}\right)$ to the pipe plane $\left(T_{p p}\right)$. The water 
temperature in the pipe is not constant and normally changes in an exponential curve along the downstream-oriented direction ( $\mathrm{z}$ direction). The temperature change in the $\mathrm{z}$ direction is majorly affected by the mass flow rate $\left(\dot{m}_{w t}\right)$ and the overall thermal transmittance from the water in the pipe to the indoor air through construction elements. Theoretical and experimental studies in the literature demonstrate that when the mass flow rate in the pipe is larger than $13 \mathrm{~kg} /\left(\mathrm{h} \cdot \mathrm{m}^{2}\right)$, the effects of the overall thermal transmittance of construction elements to temperature change in $\mathrm{z}$ direction can be neglected [46]. Given that assumption, the temperature change from the inlet to outlet can be linearized instead of using an exponential curve, and the thermal resistance from the inlet $\left(T_{w t, i n l e t}\right)$ to the point with mean water temperature $\left(T_{w t, m e a n}\right)$ in $\mathrm{z}$ direction can be given by Eq. (11).

Heat transfer from the point with mean water temperature $\left(T_{w t, m e a n}\right)$ to the pipe plane $\left(T_{p p}\right)$ through the pipe shell and concrete includes two processes, i.e., the forced convection from water to pipe shell and the thermal conduction from pipe shell to concrete. In practice, the forced convective heat transfer coefficient is mainly influenced by the mass flow rate in the pipe. Considering the water in pipe runs at a constant flow rate during operating time, the convective heat transfer coefficient can be regarded as a constant value for simplification. Thus, we can use a constant thermal resistance $\left(R_{\text {mean,pp }}\right)$ to represent the relationship between the mean water temperature $\left(T_{w t, m e a n}\right)$ and the temperature of the pipe plane $\left(T_{p p}\right)$. Note that $R_{\text {mean,pp }}$ is an unknown parameter, which is related to the geometric factors of the pipe system, such as the length, diameter, thermal conductivity of the pipe and pipe spacing. It needs to be identified using the collected data from filed tests or simulation platforms. With the values of $R_{\text {inlet,mean }}$ and $R_{\text {mean,pp }}$, the heat transferred from the inlet water to the core of the pipe plane $\left(Q_{\text {heating }}\right)$ can be given by Eq. (12). The outlet water temperature $\left(T_{w t, o u t l e t}\right)$ is determined by Eq. (13).

$$
\begin{array}{r}
R_{\text {inlet }, \text { mean }}=\frac{1}{2 c_{w t}, \dot{m}_{w t}} \\
Q_{\text {heating }}=\frac{T_{w t, \text { inlet }}-T_{p p}}{R_{\text {inlet }, \text { mean }}+R_{\text {mean }, p p}} \\
T_{w t, \text { outlet }}=T_{w t, \text { inlet }}-\frac{Q_{\text {heating }}}{c_{w t} \dot{m}_{w t}}
\end{array}
$$




\subsubsection{Model identification using linear regression}

Given the measured data of mass flow rate $\left(\dot{m}_{w t}\right), R_{\text {inlet,mean }}$ can be determined using Eq. (11). The unknown parameter $R_{\text {mean,pp }}$ can be identified using the collected data including mass flow rate $\left(\dot{m}_{w t}\right)$, inlet water temperature $\left(T_{w t, \text { inlet }}\right)$, outlet water temperature $\left(T_{w t, o u t l e t}\right)$, and pipe plane temperature $\left(T_{p p}\right)$. We can use Eq. (13) to calculate the heat $\left(Q_{\text {heating }}\right)$ transferred from the inlet water to the pipe plane based on the collected data of $\dot{m}_{w t}, T_{w t, \text { inlet }}$ and $T_{w t, o u t l e t}$. Finally, the value of $R_{\text {mean,pp }}$ in Eq. (12) can be identified with the assistance of linear regression method.

\section{Model predictive control scheme}

Three major steps are included in the online control part of MPC as shown in Fig. 3: (1) preparation/prediction of exogenous input variables including weather, occupancy and dynamic electricity prices; (2) solving optimization problem based on the predicted exogenous inputs and updated current state filtered by the Kalman filter; (3) control implementation and measurement. 


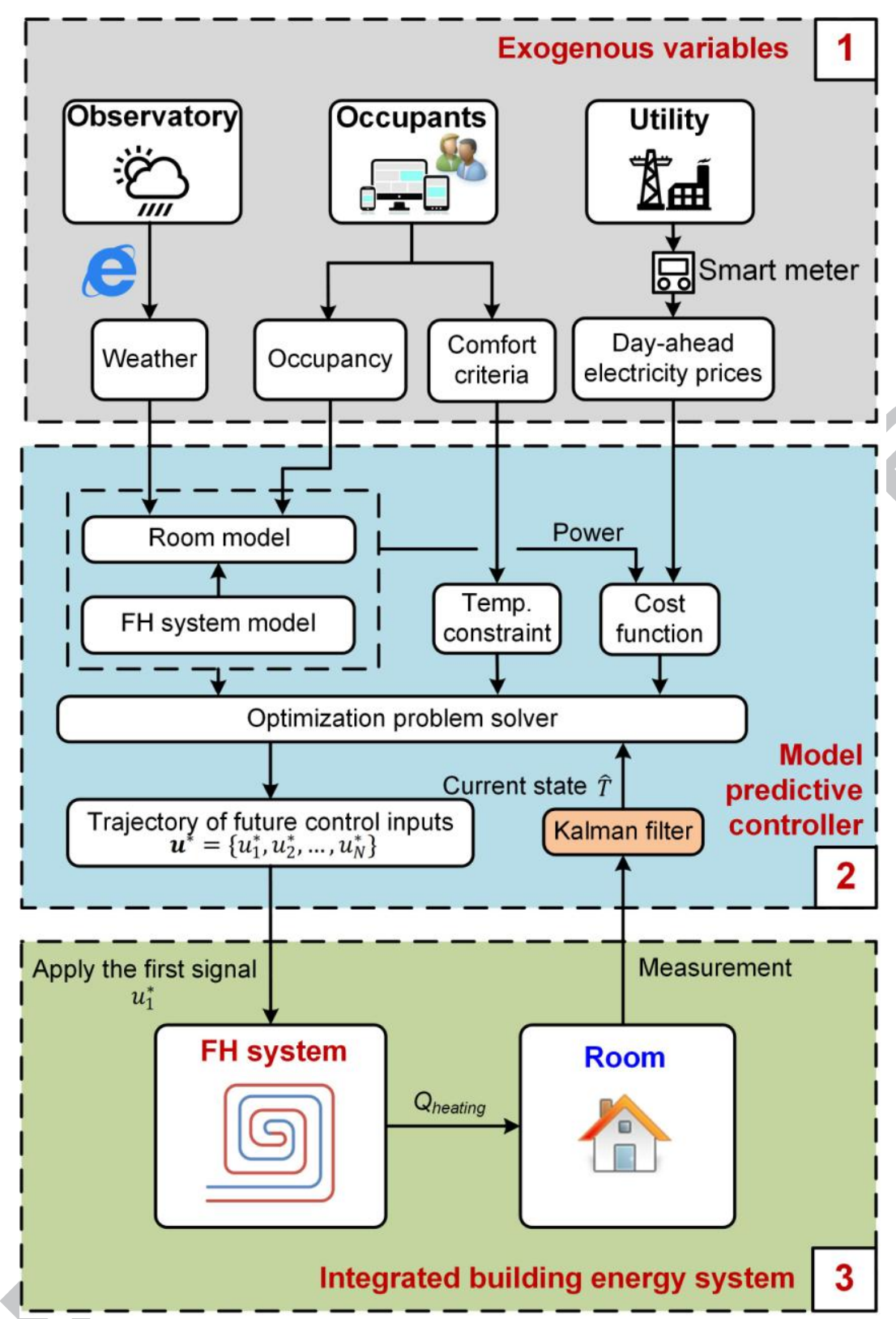

Fig. 3. Flow chart of online model predictive control for FH systems.

\subsection{Preparation/prediction of exogenous input variables}

Weather conditions, such as outdoor air temperature and solar radiation, influence the room thermal dynamics, which can be obtained from local observatory or from prediction models. The integrated building energy system model used in the MPC controller in this study makes predictions regarding system dynamics based on local weather forecasts. Occupancy prediction plays significant role in the model-based building climate control [47, 48]. The occupancy pattern determines the internal heat gain and the control range of indoor air temperature over the prediction horizon. In a practical implementation, the occupancy information can either be pre-set by customs or obtained from smart 
mobile devices and Internet-of-Things devices [49]. The occupancy in this study is pre-specified for simplicity purpose. The day-ahead electricity prices used in the optimization problem are the historical whole-sale electricity price excluding taxes, which in the present case study are obtained from the Nordic power market of Nord Pool [50].

\subsection{Formulation and solution of optimization problems}

A general MPC framework includes four parts: a cost function, constraints, system dynamics, and the current state [32]. The objective of the MPC controller for FH systems is to minimize the operating cost over the prediction horizon $N$ while keeping the indoor air temperature in the pre-specified ranges. The optimization problem for MPC of FH systems is formulated as Eqs. (14) - (19).

$$
\min _{u_{1}, u_{2}, \ldots, u_{N-1}} \sum_{k=1}^{N-1}\left(u_{k} / C O P\right) \Delta t \cdot D A P_{k}+\rho_{e} e_{k}
$$

subject to

$$
\begin{gathered}
x_{k+1}=A_{d} x_{k}+B_{d} u_{k}+E_{d} d_{k} \\
y_{k}=C_{d} x_{k} \\
y_{l b, k}-e_{k} \leq y_{k} \leq y_{u b, k}+e_{k} \\
e_{k} \geq 0 \\
u_{k}=0 \text { or } u_{k}=Q_{\text {heating }, k}
\end{gathered}
$$

where $N$ is the prediction horizon; $\Delta t$ is the prediction interval; $D A P_{k}$ is the day-ahead electricity prices (DAP) at the time step $k ; x_{k}, y_{k}$, and $d_{k}$ are the state vector, output vector, disturbance vector in the state-space system model, respectively; $w_{k}$ and $v_{k}$ are the process and measurement noise, respectively, which are assumed to be independent, white and with normal distribution; $A_{d}, B_{d}, C_{d}, E_{d}$ are the state-space matrices of the discrete-time state-space model; $u_{k}$ is the input heating from inlet water to pipe plane at the time step $k$; COP is the coefficient of performance of the heat pump, which varies with the type, ambient medium temperature (air/ground) at the evaporate side, and the water temperature at the condenser temperature. Considering the ambient medium temperature and the water temperature at the condenser side almost remain constant under the normal operating conditions, a typical constant value of COP [51], i.e., 3, is chosen for the case study in this paper.

The objective function, Eq. (14), aims at minimizing the operating cost over the prediction horizon. As long as the constraints are not violated, the optimal provided heating remains at $0 \mathrm{~kW}$, i.e., the 
thermostat is turned off. Eqs. (15) - (16) depict the system dynamics in a state-space form. Eq. (17) is a dynamic soft constraint which keeps the indoor air temperature in the range. When the room is occupied, the indoor air temperature should remain between the upper and the lower bounds to ensure thermal comfort. However, it is possible that the temperature constraint may not be satisfied in practice, which may lead to failure in solving the optimization problem. To address this issue, we can relax the MPC problem by introducing a slack variable $e_{k}$. The hard constraint is then converted to a soft constraint which has a similar function as the dead-band plays in the on-off control. A sufficiently large penalty $\rho_{\mathrm{e}}$ is imposed on the slack variable $e_{k}$, such that the temperature constraint is met (i.e., $e_{k}$ =0) whenever possible. Eq. (19) is a dynamic constraint for the command signal, i.e., heat provided by FH system, which equals zero (thermostatic valve is turned off) or $Q_{\text {heating, }}$ (thermostatic valve is

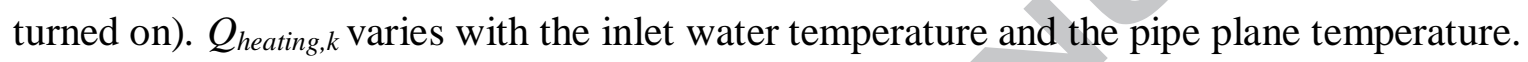

The prediction horizon, $N$, and sampling time, $\Delta t$, constitute the prediction time, $T_{p}=N \Delta t$, and play a significant role in the performance of MPC controllers. The determination of the prediction horizon is a trade-off between the accuracy of the prediction of exogenous inputs and a sufficient length of the prediction horizon. Long horizon also increases the computation time of each optimization. For the MPC of floor heating systems, the prediction horizon is normally set as $6-48$ hours because the rooms have large thermal masses and respond to the heating system very slowly [33]. Considering the long thermal response time of the target room to the FH system, the prediction horizon $N$ in this study is chosen as 12 hours, which is sufficient for the FH to prepare for the upcoming disturbances. The sampling time is the frequency at which the optimization problem is solved and at which the actuator receives the command signal. The prediction interval of the MPC controller in our study is set as 30 minutes considering the thermal response time of the room.

At the beginning of each step, the current state is needed as a starting point for the optimization. In our case, the system state includes six variables, i.e., $x=\left[T_{w, \text { ext }} T_{w, \text { int }} T_{i n} T_{m} T_{f l} T_{p p}\right]^{T}$. However, not all state variables are readily measurable in real applications. Only the indoor air temperature and floor surface temperature are assumed to be measured for the closed-loop online control in the case study. To address this issue, the Kalman filter is commonly used to optimally estimate the unmeasurable states and filter the noises in measurements [52]. The Kalman filter is an algorithm that provides a computationally efficient solution to estimate the state of a process in a way that minimizes the 
prediction mean squared error. The solution is recursive in such a way that each updated estimate of the state is computed from the previous estimate and the new measured data. As shown in Fig. 4, each Kalman filter cycle includes two steps, i.e., time update (priori estimate) and measurement update (posteriori estimate). $P, Q$ and $R$ are covariance matrices of the state estimate error, process noise and measurement noise, respectively. $\hat{x}_{k}^{\prime}$ denotes a priori state estimate at time step k. $\hat{x}_{k}$ denotes the posteriori state estimate given measurement $y_{k}$ (i.e., indoor air temperature $T_{i n}$ ) at time step k. $K_{k}$ is the Kalman gain determined by solving the discrete algebraic Riccati equation. $I$ is an identity matrix.

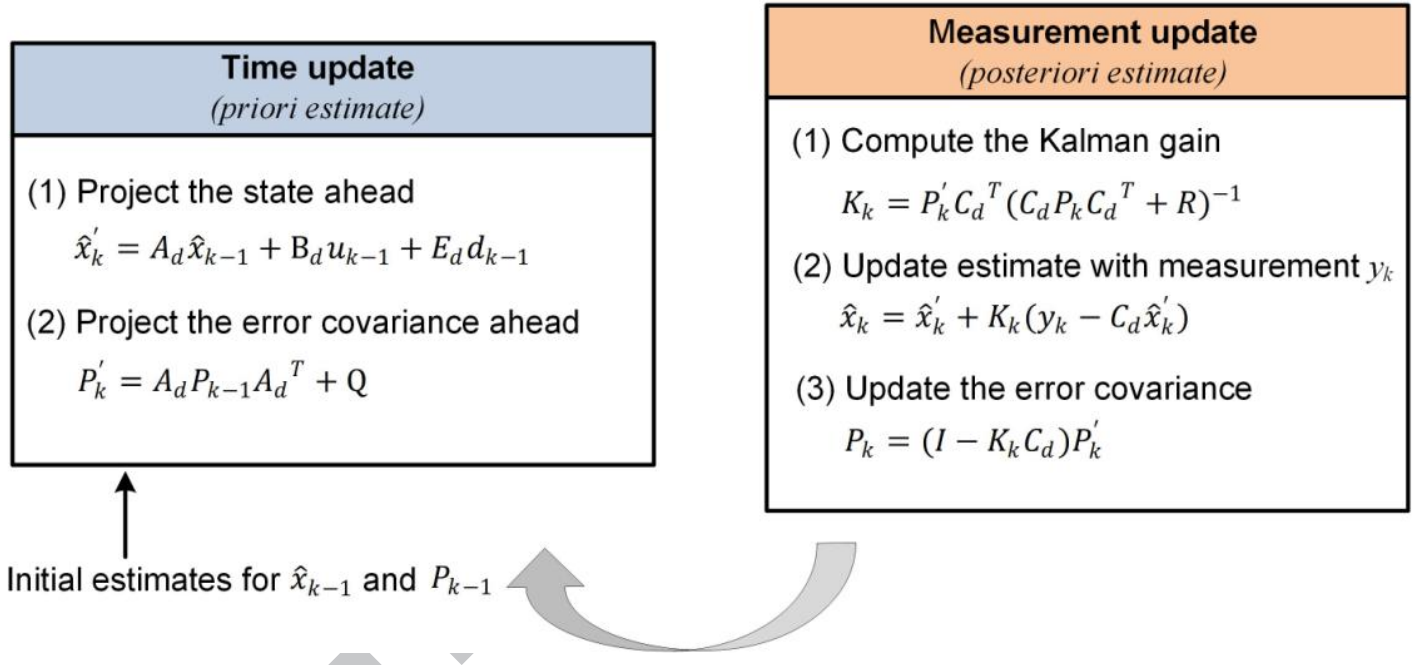

Fig. 4. Kalman filter cycle for current state estimate in MPC

\subsection{Control signal implementation}

The actuator for the FH system in the case study is a thermostatic valve. Therefore, the optimization result, i.e., the heating for $\mathrm{FH}$ system $\left(u_{k}\right)$, needs to be converted into the on-off signal for the implementation of DR control. When $u_{k}$ equals zero, the command signal for thermostatic valve is off. The conversion of the continuous solution to pulse-width modulated signal may introduce some errors in optimization, but the errors are negligible in practical applications. Model predictive control is intrinsically a feedback control, which incorporates iterative optimizations over moving prediction horizons. The optimization result at each time step is a trajectory of control signals. Only the first signal is implemented, and the rest signals are disposed. At the next time step, the optimization is repeated based on the updated current state. 


\section{Case study}

\subsection{Description of the target building and FH system}

The living room of a residential apartment in Nordhavn, Denmark is chosen to carry out the simulation-based case study. The building location, its surroundings and the apartment location in the building are presented in Fig. 5. The living room $(\mathrm{L} \times \mathrm{W} \times \mathrm{H}: 8.9 \mathrm{~m} \times 6.22 \mathrm{~m} \times 3 \mathrm{~m})$ has one south-facing exterior wall $(8.9 \mathrm{~m} \times 3 \mathrm{~m})$ and one east-facing exterior wall $(6.22 \mathrm{~m} \times 3 \mathrm{~m})$. The window-wall-ratios of the south-facing wall and the east-facing wall are 0.45 and 0.43 , respectively. The residential building is well-insulated, and the overall heat transfer coefficients of the exterior wall and the window are 0.14 and $1.4 \mathrm{~W} /\left(\mathrm{m}^{2} \cdot \mathrm{K}\right)$, respectively. The apartment is heated by water-based FH system. The outside diameter of pipe, spacing between pipes are $20 \mathrm{~mm}$ and $300 \mathrm{~mm}$, respectively. The inlet water temperature to $\mathrm{FH}$ system is regulated to be $35^{\circ} \mathrm{C}$ by a manual thermostat considering that higher temperature could damage the wooden floor panels. The zone temperature is controlled using a thermostatic electro-valve. The driver actuator of the electro-valve adopts on-off control signal. The set-point of the indoor air temperature is set as $22^{\circ} \mathrm{C}$ when the target living room is occupied during $7: 00-22: 00$.

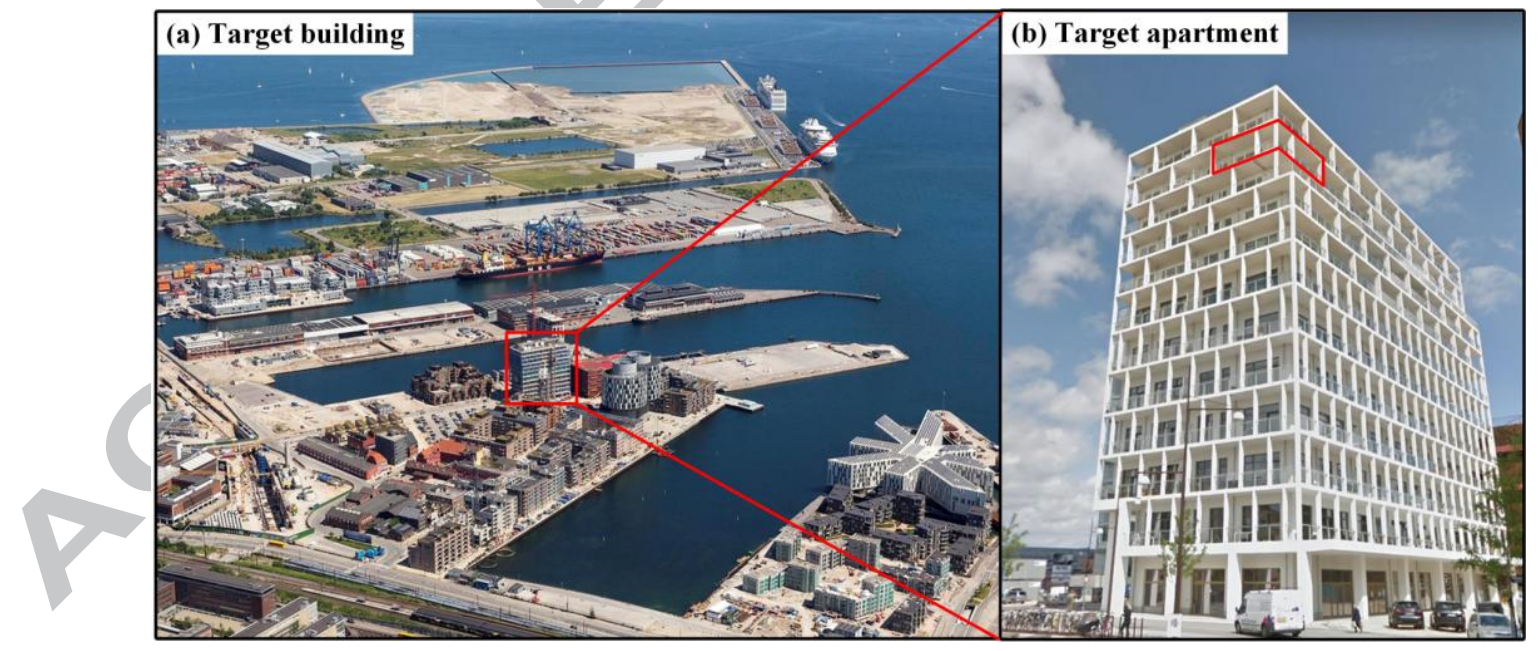

Fig. 5. (a) Building location and its surroundings and (b) apartment location in the residential building (modified from Google Maps $\left.^{\circledR}\right)$.

\subsection{TRNSYS-MATLAB co-simulation testbed}

Computer-based dynamic simulation is usually considered as an effective and reliable approach to test control performances under various operating conditions. Building energy simulation programs 
such as EnergyPlus and TRNSYS are commonly used in simulation of building thermal performance and energy performance of its HVAC system. However, the embedded controller models in these programs usually implement on-off control and PI control. As illustrated in Fig. 6, we combine TRNSYS with MATLAB to solve the problem. In the integrated building energy system, the air-conditioned room is integrated with a FH system. The building model (Type 56) in TRNSYS is used to characterize the building thermal performance under the influences of weather and occupancy. The output of the MPC controller is on-off command signal for the thermostatic electro-valve. In this study, the inherent component of Type 155 in TRNSYS is used to build the communication between the models in TRNSYS 18 (32-bit) and MATLAB 2014a (32-bit) in Windows 10 64-bit operating system. The MPC controller is designed and implemented in MATLAB using the YALMIP optimization toolbox [53] with the Gurobi optimization solver [54].

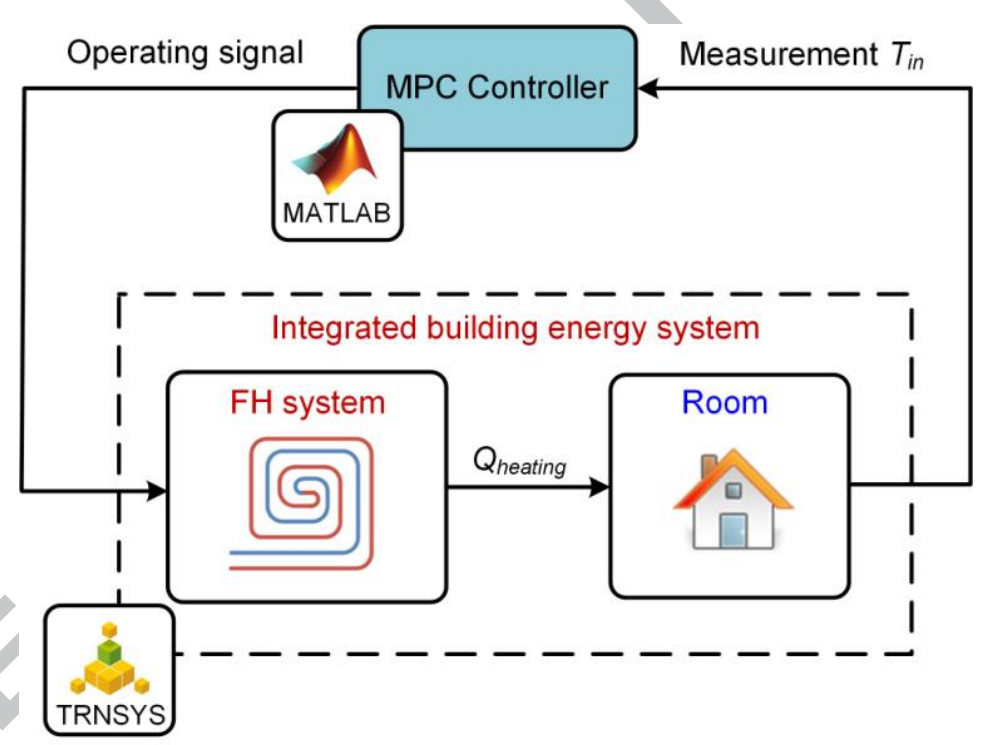

Fig. 6. A TRNSYS-MATLAB co-simulation testbed for MPC of building energy system.

\subsection{System model identification}

To identify the unknown parameters in the grey-box room thermal model, the building model in TRNSYS is first used to generate the performance data of the target room under various weather conditions. The weather data of typical meteorological year at 30-minute intervals from 1 December to 15 December, as shown in Fig. 7-a, are used for simulation tests. Based on the weather conditions, indoor air temperature and floor surface temperature data at 30-minute intervals are generated from TRNSYS to identify the room thermal model. With the identified RC values and the prediction 
interval of 30 minutes, the matrices in the discrete-time state-space model, i.e., Eqs. (8) - (9), can be determined as follows:

$A_{d}=\left(\begin{array}{cccccc}0.623 & -0.165 & 0.036 & -0.240 & 0.125 & -0.116 \\ -0.185 & -0.268 & 0.014 & 0.274 & -0.168 & 0.033 \\ -0.167 & -0.161 & 0.712 & 0.183 & 0.695 & -0.362 \\ -0.282 & 0.330 & -0.001 & 0.003 & -0.003 & -0.001 \\ 0.069 & -0.120 & 0.698 & 0.031 & -0.253 & 0.523 \\ -0.091 & 0.044 & -0.166 & 0.030 & 0.530 & 0.680\end{array}\right)_{6 \times 6} \quad ; E_{d}=\left(\begin{array}{cccc}0.035 & -0.003 & -0.097 \\ 0.173 & 0.018 & -0.093 \\ 0.046 & 0.005 & 0.001 \\ -0.091 & -0.022 & -0.174 \\ 0.009 & 0.003 & 0.001 \\ -0.001 & -0.001 & 0.001\end{array}\right)_{6 \times 3}$

$B_{d}=10^{-2}(-4.212 \quad-4.236 \quad 0.002 \quad-7.482 \quad 0.007 \quad 0.048)^{T} ; C_{d}=\left(\begin{array}{cccccc}0 & 0 & 1 & 0 & 0 & 0 \\ 0 & 0 & 0 & 0 & 1 & 0\end{array}\right)_{2 \times 6}$

The identification results for the FH system are: $R_{\text {inlet,mean }}=0.0005$ and $R_{\text {mean,pp }}=0.0012$.

As shown in Fig. 7-b, the RC room thermal model is able to predict the room thermal dynamics in a relatively high degree of accuracy. The prediction deviations between TRNSYS data and RC model data are evaluated by using both root mean square error (RMSE) and mean absolute error (MAE). The RMSEs of indoor air temperature and floor surface temperature between TRNSYS data and RC model data are $0.170^{\circ} \mathrm{C}$ and $0.135^{\circ} \mathrm{C}$, respectively. The MAEs of indoor air temperature and floor surface temperature between TRNSYS data and RC model data are $0.118^{\circ} \mathrm{C}$ and $0.099^{\circ} \mathrm{C}$, respectively. It can also be found that slightly large deviation usually occurs when the transient solar radiation reaches the peak each day, which results in the difficulty in thermal comfort control when MPC is used.
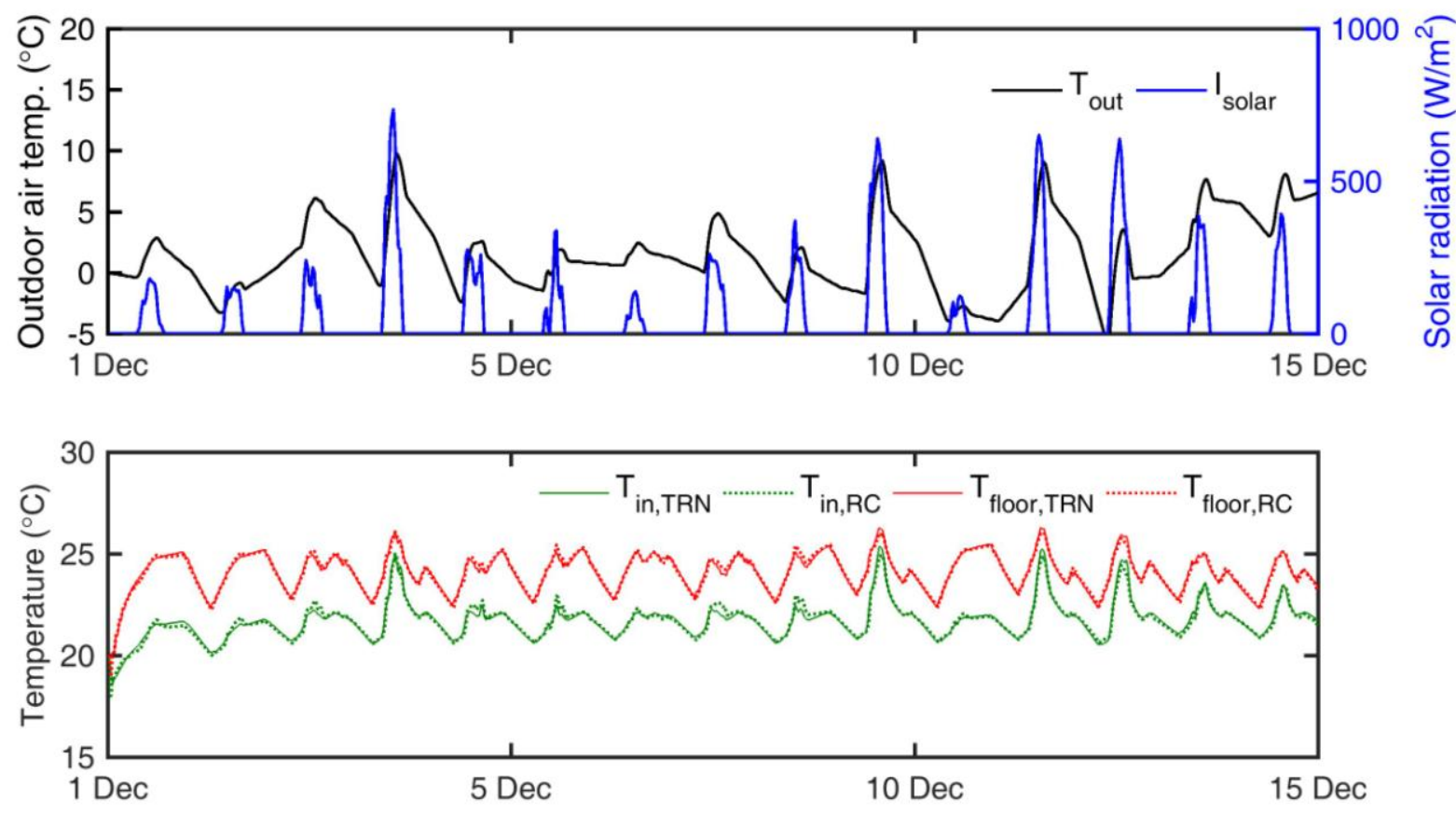
Fig. 7. (a) Weather conditions and (b) system performances (indoor air temperature and floor temperature) from TRNSYS and $\mathrm{RC}$ model when $\mathrm{FH}$ is turned on.

\subsection{System performance using different control methods}

\subsubsection{System performance using conventional on-off control}

As shown in Fig. 8, the profiles of the exogenous input variables, including weather conditions, occupancy profiles, and DAPs on seven typical winter days, are used to test the performances of both on-off controller and MPC controller in this study. A fluctuant occupancy pattern is defined to simulate the time-changing occupancy patterns. The target room is assumed to be occupied from 7:00 to 22:00. The DAPs from the Nordic power market of Nord Pool are at hourly intervals. It can be seen that DAPs at nighttime are lower than those in the daytime, which provides the potential of cost savings for residential electricity end-users. Note that during the simulation, the profiles of the exogenous input variables are gradually updated and sent to the MPC controller in the length of prediction horizon.

For comparison, the system performance using the conventional on-off control method is first tested. Detailed information on on-off control logics can be found in [55]. An on-off controller is used to control the FH system to maintain the indoor temperature at the set point. The set point of the indoor air temperature is set as $22^{\circ} \mathrm{C}$ when the target living room is occupied during 7:00 - 22:00. In this case, DAPs are only used in calculating electricity cost and it is not involved in the control method. The simulation time step is 30 minutes. 


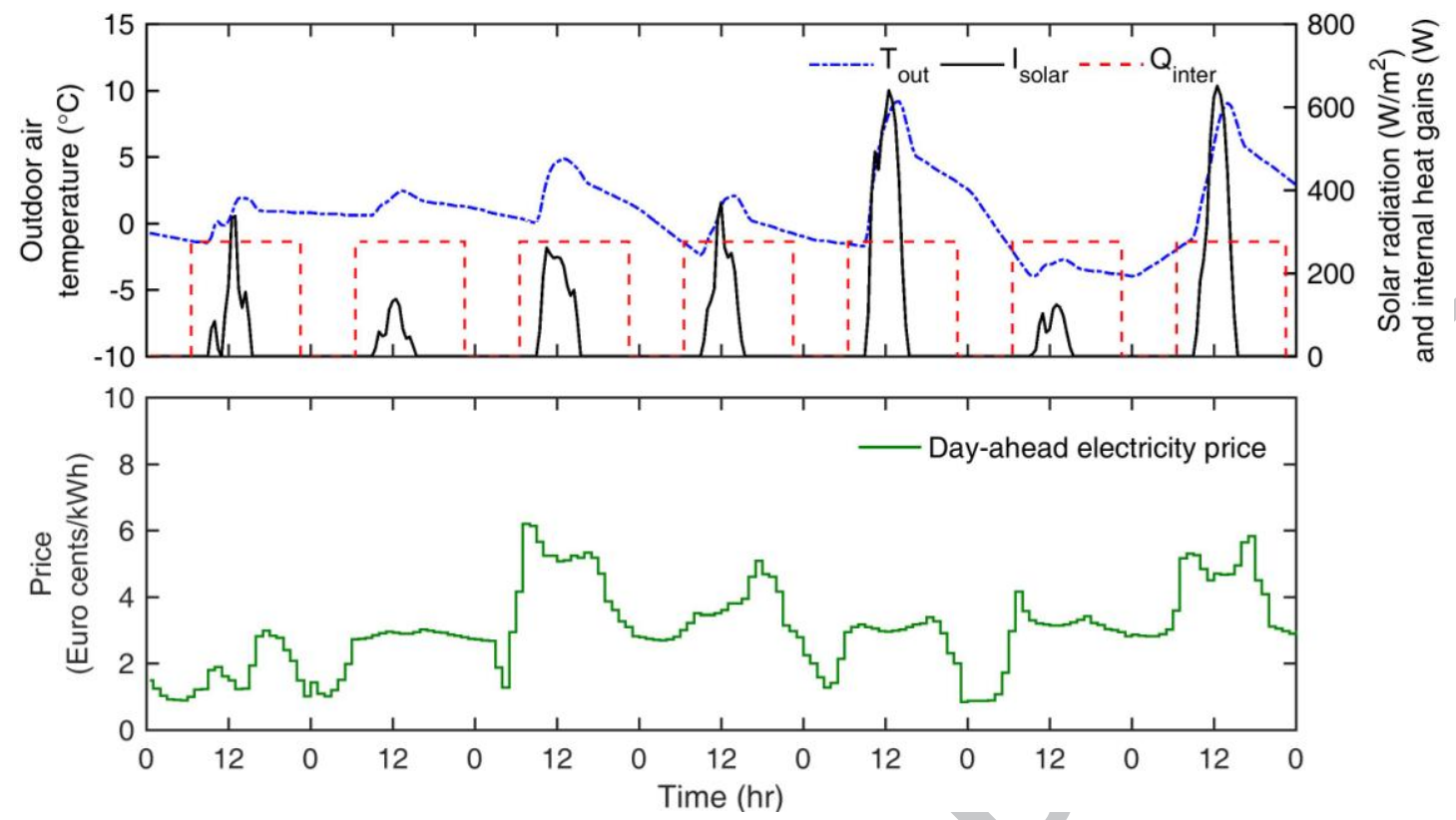

Fig. 8. Weather conditions and DAPs on seven sequential typical winter days

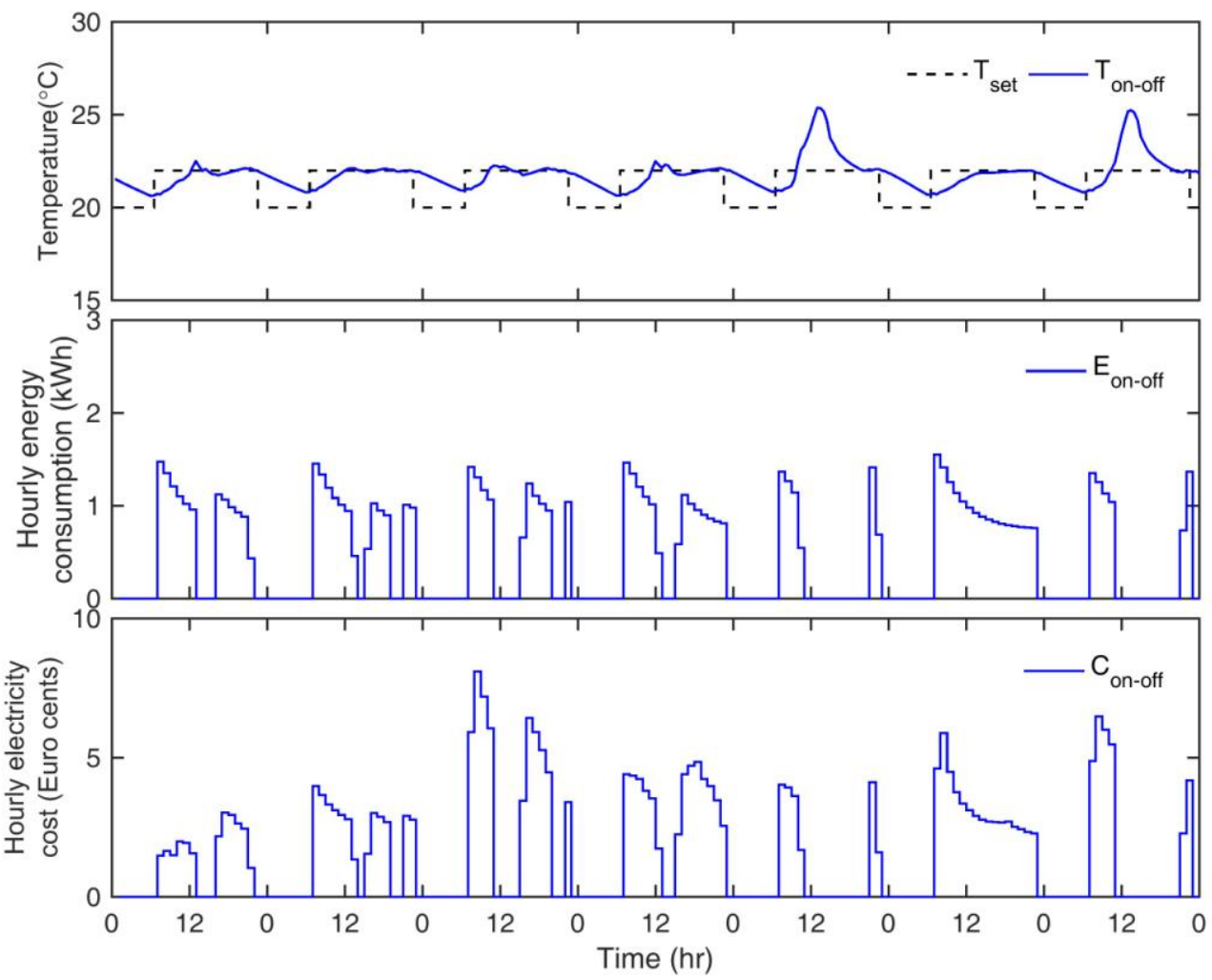

Fig. 9. System performances (i.e., indoor air temperature, power consumption, and electricity costs) when on-off controller is used.

Fig. 9 shows the performances of room and FH system under on-off control. As can be seen from the indoor air temperature profile, the on-off controller can fulfill the control objective most of the time. When the living room changes from unoccupied to occupied, the FH system takes a period of time to 
heat up the floor and the indoor air, which may cause the thermal discomfort of the occupants. It can be seen that the FH system runs in the daytime when DAPs are much higher than that at nighttime which is not cost-efficient. It is a disadvantage to the power grid when a large population of residential heating systems operate at the same time.

\subsubsection{System performance using MPC control}

For the MPC controller, the simulation time step in TRNSYS is also set as 30 minutes, i.e., prediction interval, and at each time step the MPC controller in MATLAB is called by TRNSYS and outputs the command signal to the FH system. Fig. 10 shows the system performances including indoor air temperature, energy consumption and electricity costs under the MPC control on seven winter days. For easy comparison, the performances under on-off control are also shown in the same figure.
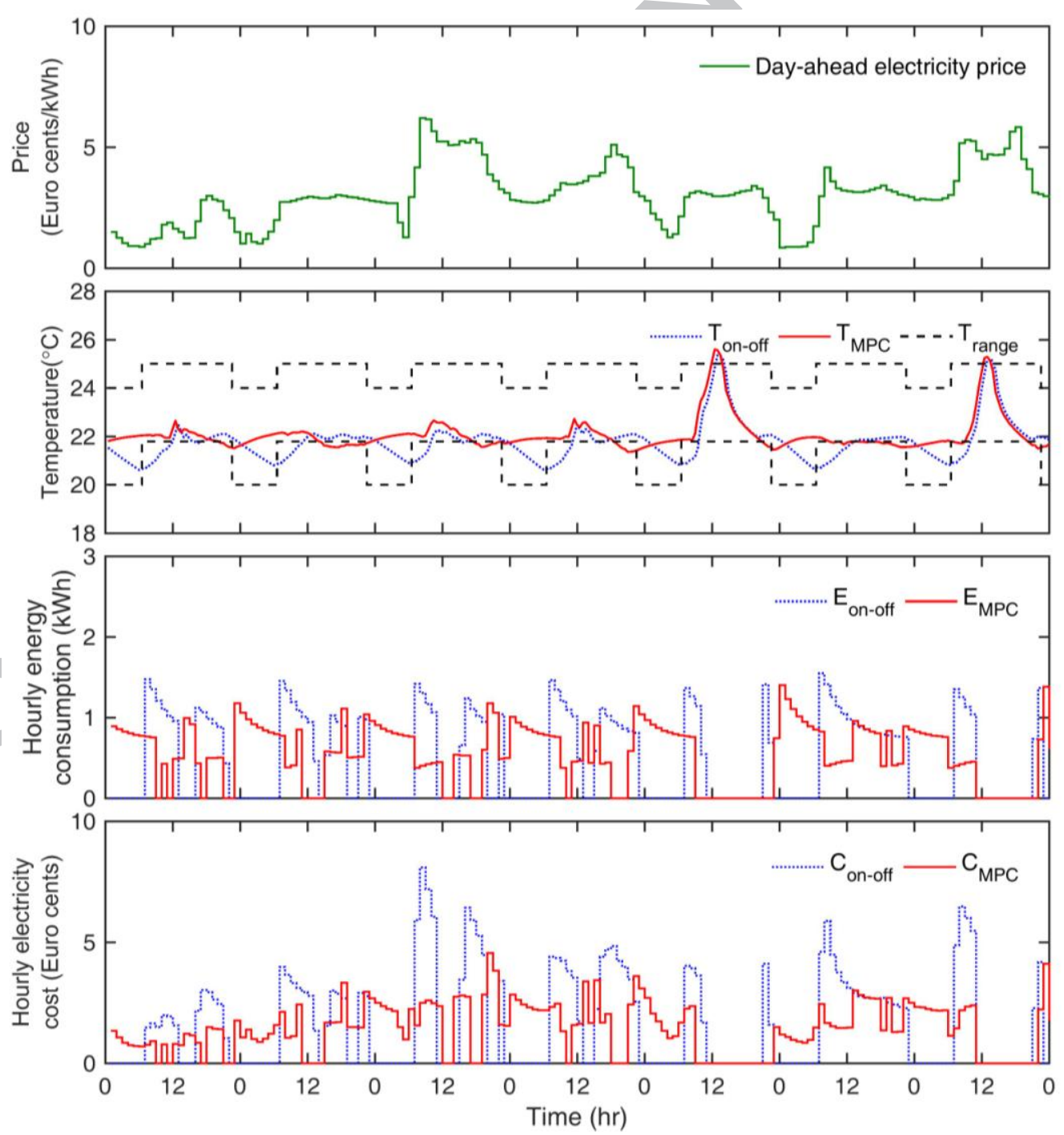

Fig. 10. (a) Day-ahead electricity prices and System performances under the on-off control and MPC on seven sequential days, including (b) indoor air temperature, (c) energy consumption and (d) electricity costs. 
As shown in Fig. 10-b, the MPC, as a new control method for FH system, can satisfactorily maintain the indoor air temperature between the upper and lower temperature bounds. Sometimes the temperature slightly exceeds the temperature bound because the prediction cannot be absolutely accurate, and some unknown random noises are added in the model of system dynamics, which is closer to the real case. Compared with the on-off control, the MPC is able to realize automatic and optimal preheating to improve the thermal comfort evaluated by the indoor air temperature at the beginning of occupancy. It makes a prediction at nighttime and realizes that the indoor air temperature at 7:00 will go below the lower bound, i.e., $22^{\circ} \mathrm{C}$. Hence, the $\mathrm{FH}$ system automatically preheats the room so that the indoor air temperature reaches at the comfortable level at the beginning of occupation. Moreover, the preheating action is optimal, which means the MPC controller can optimally determine the start-up time and duration of preheating based on the future weather conditions, price profile and thermal characteristics of the room. Temperatures outside of the bounds are considered as thermal comfort violations, which are evaluated by using RMSE in the study. As shown in Fig. $11-\mathrm{c}$, the RMSEs are reduced by $0.354^{\circ} \mathrm{C}, 0.101^{\circ} \mathrm{C}, 0.153^{\circ} \mathrm{C}, 0.248^{\circ} \mathrm{C}, 0.249^{\circ} \mathrm{C}, 0.275^{\circ} \mathrm{C}$ and $0.188^{\circ} \mathrm{C}$ on Days $1-7$, respectively.

As can be seen from Fig. 10-c, the MPC controller can also efficiently shift the energy demands from peak period (07:00 - 22:00) to off-peak period (23:00 - 6:00) and provide the energy flexibility for electric grids. The flexibility factor $(F F)$, i.e., Eq. (20), is used as a performance indicator to assess the ability to shift the energy use from on-peak to off-peak periods.

$$
\text { Flexibility factor }=\frac{E_{o f f-p e a k}-E_{\text {peak }}}{E_{\text {off-peak }}+E_{\text {peak }}}(-1 \leq F F \leq 1)
$$

where $E_{\text {off-peak }}$ and $E_{\text {peak }}$ refer to the total energy consumption during peak period (7:00 - 22:00) and off-peak period (23:00 - 6:00), respectively. The value of $F F$ ranges between -1 to 1 . The worst and optimal cases are when $F F=-1$ (i.e., energy is used only during peak period), and when $F F=1$ (i.e., energy is used only during off-peak period), respectively. Fig. 11-a shows the energy flexibility is largely achieved by using the MPC, and FFs are increased from -1 to $0.028,-0.049,-0.051,-0.042$, $0.648,-0.144$ and 0.437 on Days 1 - 7 , respectively, although the average daily energy consumption is increased by $15.81 \%$ in comparison to that under the on-off control. This is the price paid to achieve power reductions during the peak demand hours via preheating. From the prospective of 
power grids, providing a stable power reduction/shifting as required is more important than using less energy.

Due to the ability to shift energy use from high-price to low-price period, the MPC helps to reduce the total daily electricity cost, which is influenced by the weather conditions and DAPs. As shown in Fig. 11-b, the all-day electricity costs are reduced by 18.65\%, 5.58\%, 13.66\%, 9.71\%, 14.06\%, $13.30 \%$ and $1.82 \%$ on Days $1-7$, respectively.

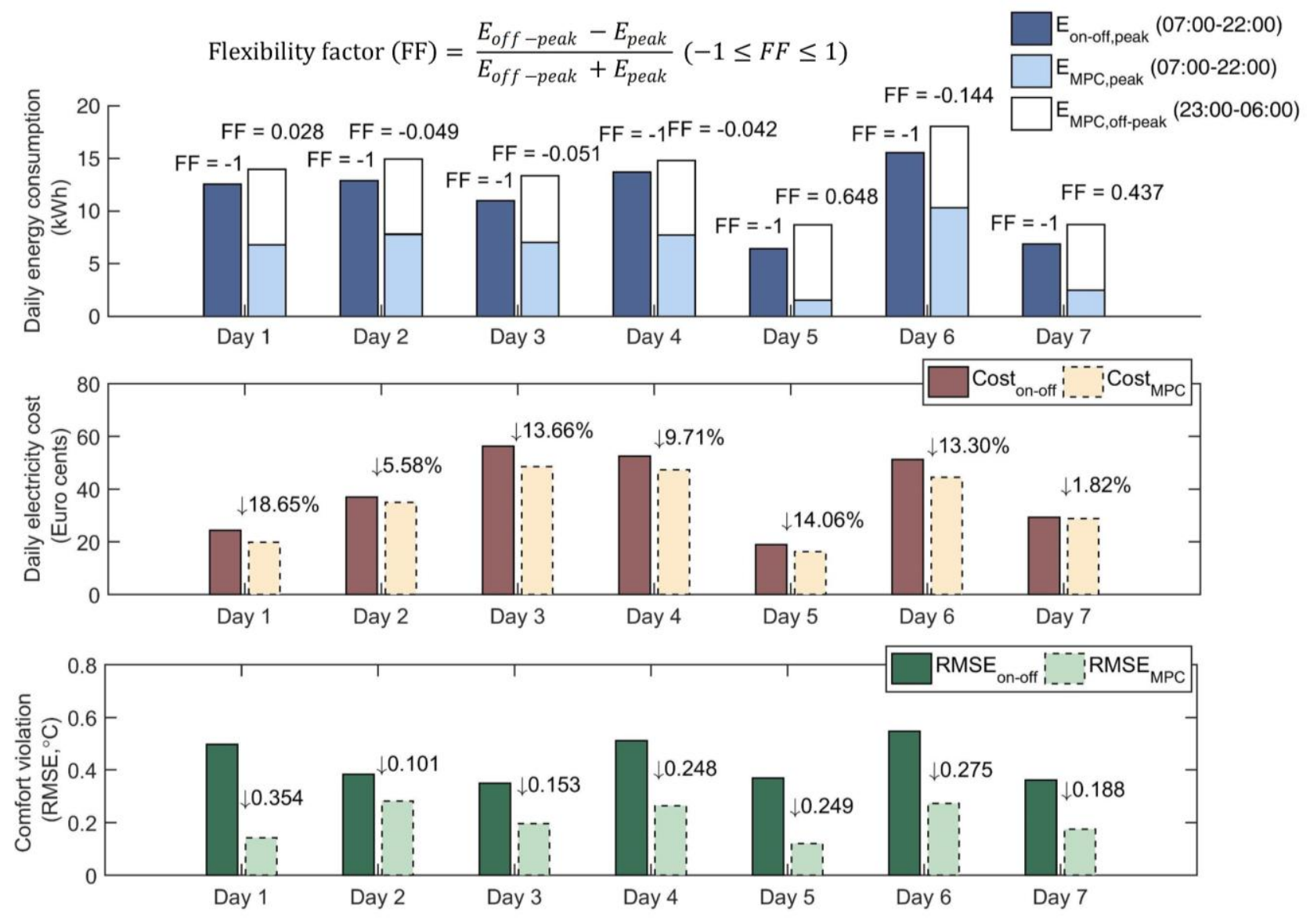

Fig. 11. Daily system performances under on-off control and MPC including (a) daily energy consumption, (b) daily electricity cost, and (c) thermal comfort violations.

Fig. 12 shows the computation time of solving the optimization problem at each time step using a PC with Intel Core i7-4790 3.60 GHz. Most computation time is seen to be less than 0.4 seconds, which is much smaller than the prediction interval 30 minutes. Therefore, the MPC controller is able to fulfill the task of online control. 


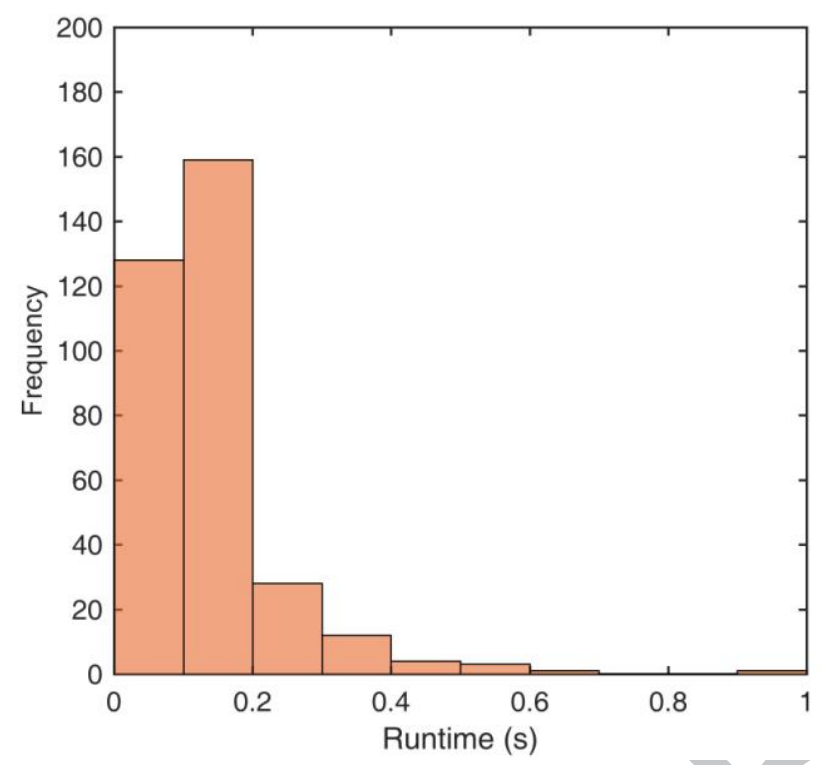

Fig. 12. Computation time for MPC controller at each time step.

\section{Conclusions and future work}

In this study, we aim to apply the MPC method to FH systems to reduce operating costs for residential DR participants considering all the influential variables including weather conditions, occupancy and dynamic electricity prices. A grey-box dynamic thermal model is developed and represented in a stochastic state-space form to predict the thermal dynamics of a room integrated with underfloor heating system. An economic MPC controller, formulated as a mixed integer linear programming problem, is then designed and tested on a TRNSYS-MATLAB co-simulation testbed.

Test results show that compared with the conventional on-off control, the MPC controller for FH systems is able to implement automatic and optimal preheating. It helps to improve the thermal comfort at the beginning of occupancy, to reduce the energy consumption during peak periods, and to reduce the daily electricity costs by $1.82 \%-18.65 \%$ for residential end-users. The start-up time and duration of preheating, energy flexibility potential, and electricity cost savings depend on weather conditions and electricity price profiles on different days. Compared with the conventional on-off controller, the economic MPC controller for FH systems is more grid-friendly and cost-efficient.

Due to the simple structure and moderate computation time, the simplified room thermal model can be used in smart home energy management system for model-based optimal control to reduce electricity bills. Energy flexibility achieved by the proposed control method can also provide financial benefits to the grid operators. It can help to avoid additional generation capacity and the 
upgrade of distribution and transmission infrastructure when a large number of residential heating systems are gird-interactive and can make demand response during peak hours.

Our future work will focus on implementing the proposed MPC method in real floor heating systems and conducting experiments to test its performance. The current study provides the theoretical guidance for the experimental validation. In the real application of MPC for built environment control, we may face the following technical challenges, including data-driven system modeling and identification, hardware and communication configuration, as well as availability and processing of input data. Besides the technical challenges, customers' willingness of initial investment and engineers' willingness to adopt new control strategies in the building automation industry are also of considerable concern.

\section{Acknowledgements}

The research work presented in this paper is financially supported by a research grant (G-YBTB) in the Hong Kong Polytechnic University (PolyU) and the Strategic Focus Area (SFA) Scheme (1-BBW7) of Research Institute for Sustainable Urban Development (RISUD) in PolyU. Furthermore, the presented work partially receives the support of the CITIES project, the SCA project, and the EnergyLab Nordhavn project in Denmark. All the supports are gratefully acknowledged.

\section{References}

[1] Xu X, Wang S, Wang J, Xiao F. Active pipe-embedded structures in buildings for utilizing low-grade energy sources: A review. Energy and Buildings. 2010;42:1567-81.

[2] Olesen BW. Radiant floor heating in theory and practice. ASHRAE journal. 2002;44:19.

[3] Sattari S, Farhanieh B. A parametric study on radiant floor heating system performance. Renewable Energy. 2006;31:1617-26.

[4] Bozkır O, Canbazoğlu S. Unsteady thermal performance analysis of a room with serial and parallel duct radiant floor heating system using hot airflow. Energy and Buildings. 2004;36:579-86.

[5] Zhou G, He J. Thermal performance of a radiant floor heating system with different heat storage materials and heating pipes. Applied Energy. 2015;138:648-60. 
[6] Xia Y, Zhang X-S. Experimental research on a double-layer radiant floor system with phase change material under heating mode. Applied Thermal Engineering. 2016;96:600-6.

[7] Weitzmann P, Kragh J, Roots P, Svendsen S. Modelling floor heating systems using a validated two-dimensional ground-coupled numerical model. Building and Environment. 2005;40:153-63.

[8] Laouadi A. Development of a radiant heating and cooling model for building energy simulation software. Building and Environment. 2004;39:421-31.

[9] Chen T. Application of adaptive predictive control to a floor heating system with a large thermal lag. Energy and Buildings. 2002;34:45-51.

[10] Weitzmann P. Modelling building integrated heating and cooling systems: Technical University of Denmark; 2004.

[11] Laustsen J. Energy efficiency requirements in building codes, energy efficiency policies for new buildings. International Energy Agency (IEA). 2008;2:477-88.

[12] Somasundaram S, Pratt R, Akyol B, Fernandez N, Foster N, Katipamula S, et al. Reference guide for a transaction-based building controls framework. Pacific Northwest National Laboratory. 2014.

[13] Electrical and Mechanical Services Department. Hong Kong Energy End-use Data 2018. 2018.

[14] Yoon JH, Bladick R, Novoselac A. Demand response for residential buildings based on dynamic price of electricity. Energy and Buildings. 2014;80:531-41.

[15] Junker RG, Azar AG, Lopes RA, Lindberg KB, Reynders G, Relan R, et al. Characterizing the energy flexibility of buildings and districts. Applied Energy. 2018;225:175-82.

[16] Qin SJ, Badgwell TA. A survey of industrial model predictive control technology. Control Engineering Practice. 2003;11:733-64.

[17] Široký J, Oldewurtel F, Cigler J, Prívara S. Experimental analysis of model predictive control for an energy efficient building heating system. Applied Energy. 2011;88:3079-87.

[18] Khanmirza E, Esmaeilzadeh A, Markazi AHD. Design and experimental evaluation of model predictive control vs. intelligent methods for domestic heating systems. Energy and Buildings. 2017;150:52-70. 
[19] Parisio A, Rikos E, Tzamalis G, Glielmo L. Use of model predictive control for experimental microgrid optimization. Applied Energy. 2014;115:37-46.

[20] O’Dwyer E, De Tommasi L, Kouramas K, Cychowski M, Lightbody G. Modelling and disturbance estimation for model predictive control in building heating systems. Energy and Buildings. 2016;130:532-45.

[21] Dahl Knudsen M, Petersen S. Demand response potential of model predictive control of space heating based on price and carbon dioxide intensity signals. Energy and Buildings. 2016;125:196-204.

[22] Oldewurtel F, Parisio A, Jones CN, Gyalistras D, Gwerder M, Stauch V, et al. Use of model predictive control and weather forecasts for energy efficient building climate control. Energy and Buildings. 2012;45:15-27.

[23] Moroşan P-D, Bourdais R, Dumur D, Buisson J. Building temperature regulation using a distributed model predictive control. Energy and Buildings. 2010;42:1445-52.

[24] Álvarez JD, Redondo JL, Camponogara E, Normey-Rico J, Berenguel M, Ortigosa PM. Optimizing building comfort temperature regulation via model predictive control. Energy and Buildings. 2013;57:361-72.

[25] Prívara S, Široký J, Ferkl L, Cigler J. Model predictive control of a building heating system: The first experience. Energy and Buildings. 2011;43:564-72.

[26] Chen X, Wang Q, Srebric J. Model predictive control for indoor thermal comfort and energy optimization using occupant feedback. Energy and Buildings. 2015;102:357-69.

[27] Ma J, Qin J, Salsbury T, Xu P. Demand reduction in building energy systems based on economic model predictive control. Chemical Engineering Science. 2012;67:92-100.

[28] Hedegaard RE, Pedersen TH, Petersen S. Multi-market demand response using economic model predictive control of space heating in residential buildings. Energy and Buildings. 2017;150:253-61. [29] Rawlings JB, Patel NR, Risbeck MJ, Maravelias CT, Wenzel MJ, Turney RD. Economic MPC and real-time decision making with application to large-scale HVAC energy systems. Computers \& Chemical Engineering. 2018;114:89-98. 
[30] Oldewurtel F, Ulbig A, Parisio A, Andersson G, Morari M. Reducing peak electricity demand in building climate control using real-time pricing and model predictive control. Decision and Control (CDC), 2010 49th IEEE Conference on: IEEE; 2010. p. 1927-32.

[31] Wanjiru EM, Sichilalu SM, Xia X. Model predictive control of heat pump water heater-instantaneous shower powered with integrated renewable-grid energy systems. Applied Energy. 2017;204:1333-46.

[32] Sultana WR, Sahoo SK, Sukchai S, Yamuna S, Venkatesh D. A review on state of art development of model predictive control for renewable energy applications. Renewable and Sustainable Energy Reviews. 2017;76:391-406.

[33] Killian M, Kozek M. Ten questions concerning model predictive control for energy efficient buildings. Building and Environment. 2016;105:403-12.

[34] Serale G, Fiorentini M, Capozzoli A, Bernardini D, Bemporad A. Model Predictive Control (MPC) for Enhancing Building and HVAC System Energy Efficiency: Problem Formulation, Applications and Opportunities. Energies. 2018;11:631.

[35] Cigler J, Gyalistras D, Široky J, Tiet V, Ferkl L. Beyond theory: the challenge of implementing model predictive control in buildings. Proceedings of 11th Rehva world congress, Clima2013.

[36] Killian M, Zauner M, Kozek M. Comprehensive smart home energy management system using mixed-integer quadratic-programming. Applied Energy. 2018;222:662-72.

[37] Mirakhorli A, Dong B. Occupancy behavior based model predictive control for building indoor climate-A critical review. Energy and Buildings. 2016;129:499-513.

[38] Oldewurtel F, Sturzenegger D, Morari M. Importance of occupancy information for building climate control. Applied Energy. 2013;101:521-32.

[39] Ma Y, Matuško J, Borrelli F. Stochastic model predictive control for building HVAC systems: Complexity and conservatism. IEEE Transactions on Control Systems Technology. 2015;23:101-16. [40] Oldewurtel F, Parisio A, Jones CN, Morari M, Gyalistras D, Gwerder M, et al. Energy efficient building climate control using stochastic model predictive control and weather predictions. American control conference (ACC), 2010: IEEE; 2010. p. 5100-5. 
[41] Qin SJ. An overview of subspace identification. Computers \& Chemical Engineering. 2006;30:1502-13.

[42] Van Overschee P, De Moor B. N4SID: Subspace algorithms for the identification of combined deterministic-stochastic systems. Automatica. 1994;30:75-93.

[43] Prívara S, Cigler J, Váňa Z, Ferkl L, Šebek M. Subspace identification of poorly excited industrial systems. 49th IEEE Conference on Decision and Control (CDC)2010. p. 4405-10.

[44] Lin Y, Middelkoop T, Barooah P. Issues in identification of control-oriented thermal models of zones in multi-zone buildings. 2012 IEEE 51st IEEE Conference on Decision and Control (CDC)2012. p. 6932-7.

[45] The MathWorks. System identification toolbox.:

https://www.mathworks.com/products/sysid.html.

[46] Air-conditioning Heating \& Refrigeration Institute. 2015 Standard for Performance Rating of Positive Displacement Refrigerant Compressors and Compressor Units. Arlington, VA, USA2015.

[47] Jia M, Srinivasan RS, Raheem AA. From occupancy to occupant behavior: An analytical survey of data acquisition technologies, modeling methodologies and simulation coupling mechanisms for building energy efficiency. Renewable and Sustainable Energy Reviews. 2017;68:525-40.

[48] Yan D, O’Brien W, Hong T, Feng X, Burak Gunay H, Tahmasebi F, et al. Occupant behavior modeling for building performance simulation: Current state and future challenges. Energy and Buildings. 2015;107:264-78.

[49] Zhou B, Li W, Chan KW, Cao Y, Kuang Y, Liu X, et al. Smart home energy management systems: Concept, configurations, and scheduling strategies. Renewable and Sustainable Energy Reviews. 2016;61:30-40.

[50] Nord Pool. Day-ahead Prices in Denmark. URL https://wwwnordpoolgroupcom/Market-data1/Dayahead/Area-Prices/DK/Hourly/?dd=DK2\&view= table. 2018. 
[51] Halvgaard R, Poulsen NK, Madsen H, Jørgensen JB. Economic model predictive control for building climate control in a smart grid. Innovative Smart Grid Technologies (ISGT), 2012 IEEE PES: IEEE; 2012. p. 1-6.

[52] Simon D. Optimal state estimation: Kalman, H infinity, and nonlinear approaches: John Wiley \& Sons; 2006.

[53] Löfberg J. YALMIP: A toolbox for modeling and optimization in MATLAB. Computer Aided Control Systems Design, 2004 IEEE International Symposium on: IEEE; 2004. p. 284-9.

[54] Gurobi Optimization I. Gurobi optimizer reference manual. URL http://wwwgurobicom. 2016. [55] Hu M, Xiao F, Wang L. Investigation of demand response potentials of residential air conditioners in smart grids using grey-box room thermal model. Applied Energy. 2017;207:324-35. 


\section{Highlights}

- A simplified model for a room integrated with floor heating system is developed.

- An advance MPC method is developed to make floor heating system grid-responsive.

- MPC can simultaneously consider weather conditions, occupancy and dynamic prices.

- MPC helps to reduce peak demands, provide energy flexibility and save costs. 